\title{
Wavelength Discrimination in the 'Visible' and Ultraviolet Spectrum by Pigeons
}

\author{
Jacky Emmerton and Juan D. Delius \\ Department of Psychology, Durham University, Durham, England*
}

\begin{abstract}
Summary. Using operant conditioning methods, the pigeon's wavelength discrimination abilities were assessed in two experiments to generate discrimination functions. Both these functions showed three minima at 460,530 and $595 \mathrm{~nm}$. In the second wavelength discrimination experiment, extending measurements into the UV spectral region, pigeons also maintained good discrimination between wavelengths within the UV range tested. A fourth minimum was indicated at the lower end of the spectral range tested (365$385 \mathrm{~nm}$ ). The results point to the complexity of the pigeon's chromatic system, which must be at least tetrachromatic, probably pentachromatic.
\end{abstract}

\section{Introduction}

It is generally agreed that the colour vision of diurnal birds is excellent. The mechanisms underlying this capability, however, are uncertain and have been the source of extensive dispute. In particular the role played by the brightly coloured oil droplets found in avian retinas has given rise to much speculation. Better knowledge about the performance characteristics of the colour vision system would put much of the argument on a more certain footing. The wavelength discrimination function, that plots across the spectrum the minimum wavelength differences that an animal can usefully distinguish, typifies the most salient property of a colour vision system. For the pigeon, the best studied of the avian species, this function has been measured, albeit incompletely; sev-

\footnotetext{
* Present address: Experimentelle Tierpsychologie, Psychologisches Institut, Ruhr-Universität Bochum, D-4630 Bochum 1, Federal Republic of Germany
}

Abbreviations: $S+$ positive stimulus; $S$ - negative stimulus eral times. A first function obtained by Hamilton and Coleman in 1933 had suggested that the pigeon's colour vision was similar to that of man. Later determinations (e.g., Blough, 1972; Riggs et al., 1972; Schneider, 1972; Wright, 1972a) have definitely corrected that erroneous early impression but they have not yet yielded sufficiently concordant functions. Moreover, none of the measurements has extended into the near-ultraviolet. This has become important since it has been demonstrated that pigeons are visually sensitive in this spectral region (see Kreithen, 1978; Wright, 1972b). We now report two experiments intended to improve this situation.

\section{Experiment I: Wavelength Discrimination in the 'Visible' Spectrum}

\section{Methods}

5 adult pigeons (Columba livia) of local homing stock were used. They were maintained at $80 \%$ of their normal body weight.

The Skinner box, housed in a dark room, had two pecking keys $(2.5 \mathrm{~cm} \mathrm{dia})$ on one wall and a food hopper on the opposite wall. On the floor between the two walls was a platform that activated a microswitch when depressed. The box interior was painted matt grey and could be illuminated with a strip light attached to the ceiling. The keys, positioned side by side, were made of frosted perspex. The stimuli were back-projected onto them. Conventional electromagnetic programming and counting equipment controlled the events and recorded the responses.

\section{Procedure}

The pigeons were first shaped to peck the keys illuminated with white light for $6 \mathrm{~s}$ food access. Side preferences were broken down by temporarily disconnecting the preferred key. At the end of pretraining the animals operated on a fixed ratio of 5 responses per reinforcement.

For the experiment proper narrow horizontal bar stimuli $(10 \times$ $1 \mathrm{~mm}$ ) were back-projected onto the response keys (RK) with two identical optical systems (Fig. 1), each consisting of a $50 \mathrm{~W}$ 


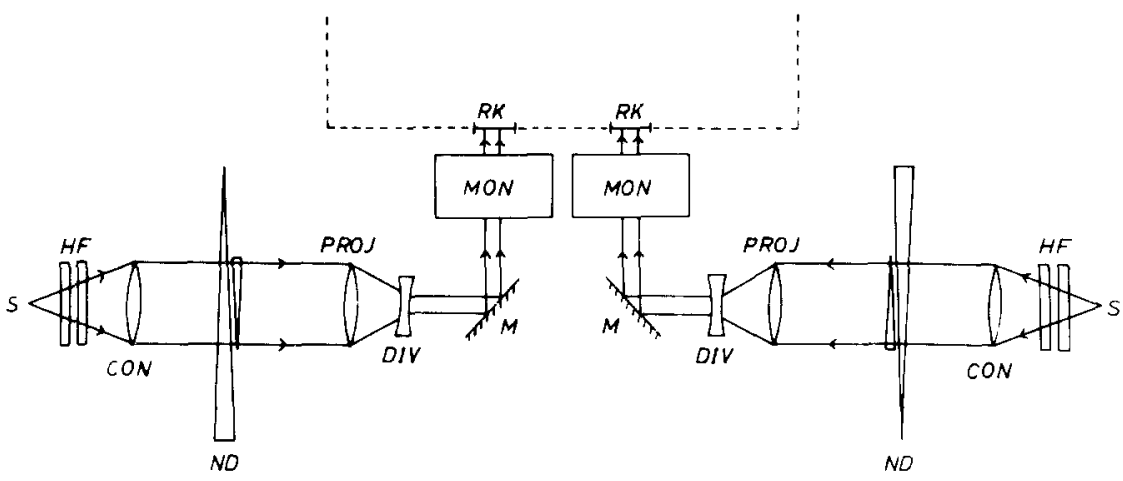

Fig. 1. Optical system, providing coloured horizontal bar stimuli which were back-projected onto the response keys of the Skinner box. See text for details

tungsten-iodine lamp (S), heat filters (HF), achromatic doublet condensor (CON) and projection (PROJ) lenses, a low power diverging lens (DIV), a front-silvered mirror (M), and a grating monochromator (Hilger-Watts D 292) (MON) set to give a $6.6 \mathrm{~nm}$ half-bandwidth. The monochromators' calibration was checked with spectral discharge lamps. Stimulus luminance was controlled using compensated neutral density wedges (ND).

To obtain stimuli of approximately equal pigeon subjective brightness we first equated the stimulus luminance over the range of 400 to $680 \mathrm{~nm}$ to $17 \pm 0.85 \mathrm{~mL}$ using an SEI photometer. Then, applying Blough's (1957) comparative data on the human and pigeon spectral sensitivity, we made further neutral density wedge adjustments to yield an equal pigeon luminance spectrum. Later, when a Hilger-Watts FT 17 thermopile was available, we could confirm that these adjustments were satisfactory. The neutral wedge settings that were thus determined, and which corresponded to the various wavelengths, were used throughout.

Trials began with the stimuli being displayed on the keys. If the animal delivered five consecutive pecks to the positive stimulus $(\mathrm{S}+)$ it was rewarded with $5 \mathrm{~s}$ illuminated food access followed by a $3 \mathrm{~s}$ inter-trial interval with the ceiling illumination on. If it gave five pecks to the negative stimulus $(\mathrm{S}-)$ it was punished by an $8 \mathrm{~s}$ wait with the ceiling light on. If it changed keys before completing the requirement of five consecutive pecks, it had to make good the responses made on the previous key with an equal number of pecks on the new key before the count of five began. If, because of multiple key changeovers, no reinforcement had been delivered after a maximum of 10 responses then the 15 th peck by itself decided the kind of reinforcement delivered. The $8 \mathrm{~s}$ reinforcement intervals allowed time for the experimenter to adjust stimulus settings between trials. Stimulus positions were changed semi-randomly.

Two daily sessions of 20 trials each were given. A series of sessions began with the animals having to discriminate a pair of wavelengths differing by 50 to $100 \mathrm{~nm}$. After the subject met the criterion of at last $90 \%$ correct responses in two consecutive sessions the $\mathrm{S}-$ wavelength was shifted towards the $\mathrm{S}+$ wavelength by a $10 \mathrm{~nm}$ step. If the animal again met the criterion in the following session the $\mathrm{S}$ - was again altered. If it did not, the change was delayed until after a further session. As the subject's performance deteriorated the steps were first reduced to $5 \mathrm{~nm}$ and then to $2 \mathrm{~nm}$. The procedure continued until the performance fell to a level of $70 \%$ or less correct on two consecutive sessions. The wavelength of the $S-$ at this point was then recorded together with that of the $S+$ that had remained unaltered throughout. A new series was begun using a new pair of stimuli. Each subject completed 15 such series with stimulus pairs within the range 400 to $680 \mathrm{~nm}$. For 3 of the birds the $\mathrm{S}+$ was, except at the lowest
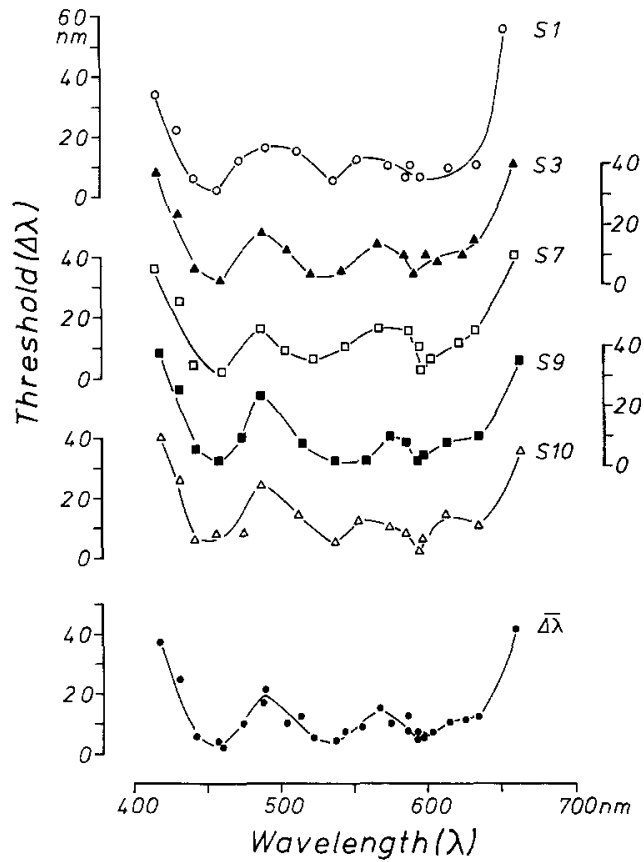

Fig. 2. Wavelength discrimination functions for individual subjects. $S 1-10$, and mean results $(\overline{\Delta \lambda})$ in Experiment $I$

spectral range, of longer wavelength than $\mathrm{S}-$. For the other 2 subjects this was reversed.

\section{Results}

The wavelength differences between the $\mathrm{S}+$ and the $\mathrm{S}-$ when the bird's performance had just fallen below $70 \%$ correct were taken as threshold differences. For each subject these values were plotted at the midpoint between the corresponding $\mathrm{S}+$ and $\mathrm{S}$ - wavelengths. Mean thresholds were calculated for the 5 subjects (Fig. 2). For this, the thresholds obtained with a given $\mathrm{S}+$ wavelength and under the same conditions (i.e. with the $\mathrm{S}-$ either greater or smaller) were averaged. 
Curves were fitted by eye. The mean function showed three regions of optimum discrimination at about 595 , 530 and $460 \mathrm{~nm}$. The individual discrimination functions were similar, each showing 3 minima.

Evidence that became available as the above experiment was completed and which suggested that pigeons could perceive ultraviolet light (Wright, 1972 b) made necessary a further experiment. It became desirable to extend the measurements to this spectral range but also to exclude that results obtained at long stimulus wavelengths might have been contaminated by ultraviolet sidebands that, although weak, were not specifically blocked in the above experiment.

\section{Experiment II: Wavelength Discrimination in the UV and 'Visible' Spectrum}

\section{Method}

One pigeon became ill and was discarded early on in this experiment. Two subjects responded rather poorly so that about two thirds of the data were collected from the remaining two birds.

The basic method of this second experiment was similar to that of the first experiment. The same chamber was used but the keys were replaced by ground glass ones known not to fluorescent with UV light. The optics were replaced by a system capable of producing stimuli down to $360 \mathrm{~nm}$.

A $75 \mathrm{~W}$ high pressure xenon lamp (Xe) provided two beams which were collimated by achromatic doublet lenses $\left(\mathrm{L}_{1,2}\right)$ (Fig. 3 ). After reflection off front-silvered mirrors (M), each beam was attenuated (without altering stimulus configuration and independent

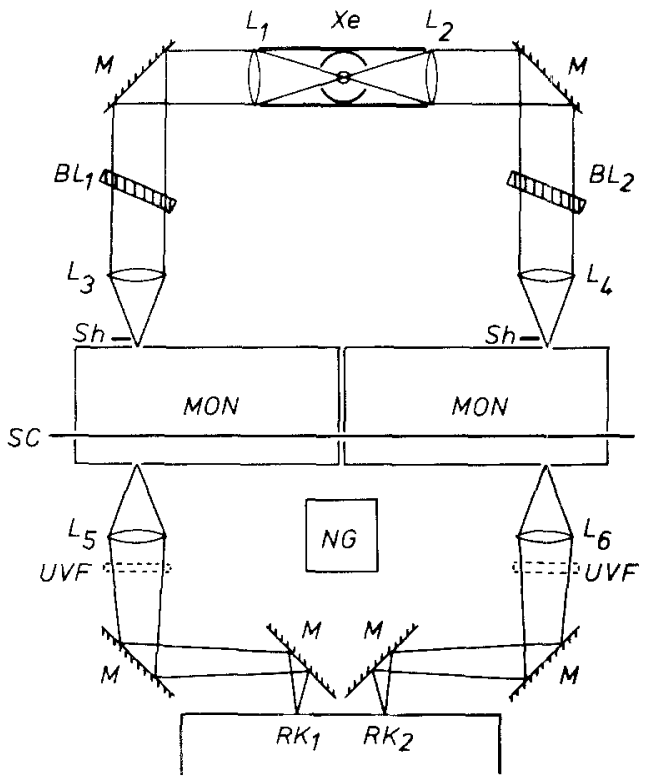

Fig. 3. Optical system by which monochromatic stimuli, each consisting of a bright central square extending into a dimmer vertical bar, were back-projected onto the response keys of the Skinner box. For details see text of wavelength) by rotation of specially constructed blinds $\left(\mathrm{BL}_{1,2}\right)$, mounted on stepper motors. Further lenses $\left(L_{3,4}\right)$ focused the light onto the entrance slits of two Hilger-Watts D 330 grating monochromators (MON), driven by stepper motors. The stimuli could be occluded by solenoid-operated shutters (Sh). A lens and mirror system focused the monochromatic light (with a half-bandwidth of $4.8 \mathrm{~nm}$ ) onto the back of each response key $\left(\mathrm{RK}_{1,2}\right)$ on the Skinner box. Wratten 2B filters (UVF) were used to suppress UV sidebands for nominal wavelengths above $600 \mathrm{~nm}$. Stray light was minimized with a screen (SC) and by shielding the xenon lamp. The stepper motor noise was masked by white noise emanating from a loudspeaker (NG).

The wavelength settings of both monochromators were checked with a mercury discharge lamp. The stimuli on the pecking keys appeared as two centrally located bright squares $(3 \times 3 \mathrm{~mm})$ with a fainter $3 \mathrm{~mm}$ wide vertical band above and below. The irradiance of the bright central stimulus square was calibrated with the thermopile. The blind of each optical channel was set to give a spectrum of equal subjective brightness for pigeons according to an electroretinographic spectral sensitivity function that we had determined previously (Delius and Emmerton, 1979) and which showed substantial agreement with preceding data (Blough, 1957; Graf and Norren, 1974). This was done at $10 \mathrm{~nm}$ wavelength intervals between 360 and $660 \mathrm{~nm}$. Settings for intermediate wavelengths were interpolated. These settings were stored in the computer so that the correct blind position could be set up automatically for every wavelength.

The luminance of the $580 \mathrm{~nm}$ stimulus measured with the photometer was $5.4 \mathrm{~mL}$. During the experiment the intensity of either the $\mathrm{S}+$ or $\mathrm{S}-$ was randomly varied by $0.1 \log$ units from trial to trial to further prevent brightness being used as a cue.

The equipment was fully controlled by an IBM 1130 computer with a WDV interface. Choice of the $\mathrm{S}+$ led to $4 \mathrm{~s}$ food access and incorrect responding to $4 \mathrm{~s}$ illumination of the ceiling light. When necessary the stimulus settings were automatically altered during these intervals. A printout recorded the stimulus wavelengths and the animal's response in each trial. The number of correct choices was evaluated every 10 trials.

For each new wavelength pair a series started with training sessions of 50 trials with the $\mathrm{S}+$ and $\mathrm{S}$ - wavelengths remaining constant until a criterion of at least 9 choices being correct in each of the last two blocks of 10 trials had been reached. Mostly this criterion was achieved within the initial training session.

These sessions were followed by 'titration' sessions of 150 trials. During these sessions the $\mathrm{S}+$ was always the same but the $\mathrm{S}$ - wavelength could change after each block of 10 trials, depending on the number of correct responses achieved in the previous block. If the score had been 7 , the $\mathrm{S}-$ wavelength remained the same on the next trials. Following higher or lower scores the wavelength difference was either decreased or increased by one fifth to the nearest integer of the preceding wavelength difference.

Several titration sessions were run, the first session always beginning with the same $S-$ as in the training session. The initial wavelength difference in later sessions was reduced if the previous session had yielded a run of high scores. This helped to obtain an intermediate level of correct responding more quickly.

\section{Results}

Raw scores were the numbers of correct choices per block of 10 trials for a particular wavelength difference. In a titration session a series of scores of 9 or 10 was obtained before the diminishing wavelength 
Table 1. Raw scores from one complete titration session for an individual bird tested at $360 \mathrm{~nm}$

\begin{tabular}{|c|c|c|c|c|}
\hline $\begin{array}{l}\text { Block of } \\
10 \text { trials }\end{array}$ & $\begin{array}{l}\text { Positive } \\
\text { wavelength }\end{array}$ & $\begin{array}{l}\text { Negative } \\
\text { wavelength }\end{array}$ & $\begin{array}{l}\text { Wavelength } \\
\text { difference }\end{array}$ & $\begin{array}{l}\text { Discrimina- } \\
\text { tion score }\end{array}$ \\
\hline 1 & 360 & 430 & 70 & 8 \\
\hline 2 & 360 & 415 & 55 & 10 \\
\hline 3 & 360 & 403 & 43 & 10 \\
\hline 4 & 360 & 394 & 34 & 10 \\
\hline 5 & 360 & 387 & 27 & 10 \\
\hline 6 & 360 & 381 & 21 & 10 \\
\hline 7 & 360 & 376 & 16 & $-\frac{\pi 0}{9} 7$ \\
\hline 8 & 360 & 372 & 12 & 81 \\
\hline 9 & 360 & 369 & 9 & 71 \\
\hline 10 & 360 & 369 & 9 & 8 \\
\hline 11 & 360 & 367 & 7 & 61 \\
\hline 12 & 360 & 369 & 9 & 81 \\
\hline 13 & 360 & 367 & 7 & 7 \\
\hline 14 & 360 & 367 & 7 & 71 \\
\hline 15 & 360 & 367 & 7 & $6 \mathrm{~J}$ \\
\hline
\end{tabular}

The "plateau' of high scores in the initial blocks were not used for the threshold evaluation; the data enclosed by dashed lines were plotted and fitted by a least squares line

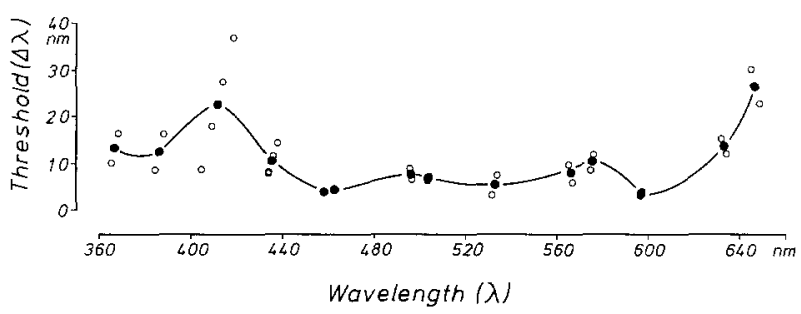

Fig. 4. Mean wavelength discrimination function from Experiment II. - pooled means, $O$ average thresholds for individual subjects

differences produced scores oscillating around 7 out of 10 correct choices. In the data analysis, the initial high score plateau was ignored. Only the last score of this plateau plus the scores on subsequent blocks of trials were considered. The raw scores for one complete titration session are presented in Table 1 as an example. These block scores were plotted versus the corresponding wavelength differences, separately for each $\mathrm{S}+$ wavelength tested. A least squares line was then fitted to the data. By interpolation the wavelength difference threshold was calculated for a block score of 7 , corresponding to the threshold discrimination level of $70 \%$ correct used in Experiment I.

To allow for adaptation to the titration procedure the results of the first titration sessions of each series were not used. Averages of the thresholds obtained in the second and third sessions were calculated. Overall means were obtained by pooling the results of individuals tested at a particular positive wavelength and under the same stimulus condition. A mean wavelength discrimination function (Fig. 4) was constructed as in Experiment I.

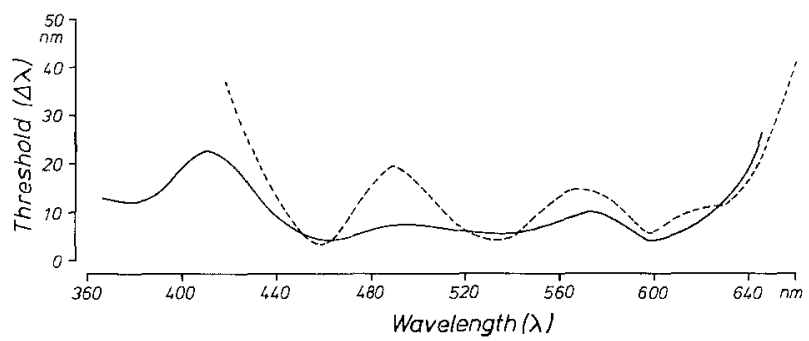

Fig. 5. Comparison of mean wavelength discrimination functions obtained from the same subjects

\section{Discussion}

The results from both Experiments I and II indicate that the wavelength discrimination function has 3 minima at 460, 530 and $595 \mathrm{~nm}$ (Fig. 5). A potential UV contamination in Experiment I was therefore not critical. Experiment II however indicates a possible fourth minimum at $365-385 \mathrm{~nm}$.

For comparison, the regions of best wavelength discrimination reported in other studies using pigeons are summarized in Table 2 . The agreement in the middle- and long-wavelength domain is good but the positions of short-wavelength minima are discordant. In several of the studies listed in Table 2, a minimum occurs at about $500 \mathrm{~nm}$ rather than at $460 \mathrm{~nm}$, as in our own experiments. On the other hand, minima were found at both these locations by Jitsumori (1978). A comparison of our own two sets of results (Fig. 5) also showed the largest discrepancy in the $500 \mathrm{~nm}$ region.

Short wavelength visual functions seem generally to be difficult to measure accurately and appear to be particularly affected by testing conditions (Delius, 1968; Graf and Norren, 1974). The discrepancies may be due to the different stimulus luminances employed but an analysis in this respect yielded equivocal results. Other differences in stimulus presentation and test methods may have interfered. Our own results, obtained under similar stimulus and testing conditions, suggest that a decrease in luminance produces either a progressive shift from a $460 \mathrm{~nm}$ minimum towards one at longer wavelengths, the results of Experiment II being intermediate or, indeed, another minimum in addition to that at $460 \mathrm{~nm}$ appears at $500 \mathrm{~nm}$ (Jitsumori, 1978).

The pigeon's use of the red or yellow retinal fields to observe stimuli may be another source of discrepancy. Martin and Muntz (1979) found divergences in the spectral sensitivities of these two fields and they also suspected differences in colour discrimination ability. A colour vision inhomogeneity between the two fields has been reported on the basis of more indirect evidence by Delius et al. (see Delius and Em- 
Table 2. Summary of results from wavelength discrimination experiments and related studies on pigeons

\begin{tabular}{|c|c|c|c|c|c|c|}
\hline \multirow[t]{2}{*}{ Present study } & $\begin{array}{c}X \\
460\end{array}$ & - & $x$ & $\begin{array}{c}\mathrm{x} \\
505\end{array}$ & & \multirow[b]{3}{*}{$\begin{array}{l}\text { Wavelength discrimination } \\
\text { jumping stand }\end{array}$} \\
\hline & $\begin{array}{c}400 \\
1\end{array}$ & & $\begin{array}{c}300 \\
1\end{array}$ & 1 & & \\
\hline Hamilton and Coleman (1933) & 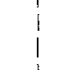 & $\begin{array}{c}\mathrm{x} \\
500\end{array}$ & $\frac{1}{1}$ & $\begin{array}{rl}\times & 1 \\
580 & 1\end{array}$ & & \\
\hline Riggs et al. (1972) & 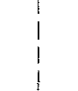 & - & $\begin{array}{c}1 \\
x \\
530\end{array}$ & $\begin{array}{r}x ! \\
585\end{array}$ & & $\begin{array}{l}\text { Wavelength discrimination } \\
\text { electroretinogram }\end{array}$ \\
\hline Wright (1972a) & $i$ & $\begin{array}{c}x \\
500\end{array}$ & $\begin{array}{l}1 x \\
540\end{array}$ & $\frac{1}{600}$ & & Hue discrimination detection \\
\hline Wright and Cumming (1971) & 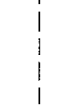 & & $\begin{array}{l}1 \\
1 x \\
540\end{array}$ & $\begin{array}{c}1 \\
x \\
595\end{array}$ & & $\begin{array}{l}\text { 'Colour naming' function } \\
\text { matching to sample }\end{array}$ \\
\hline Jitsumori (1978) & $\begin{array}{c}x \\
450\end{array}$ & $\begin{array}{c}x \\
510\end{array}$ & $\begin{array}{l}1 \\
x \\
530\end{array}$ & $\begin{array}{l}1 \mathrm{x} \\
600\end{array}$ & & Post-discrimination gradients \\
\hline Schneider (1972) & $\frac{1}{i} ?$ & $\begin{array}{c}x \\
500\end{array}$ & $\begin{array}{l}1 x \\
540\end{array}$ & $\begin{array}{l}1 \\
600\end{array}$ & & $\begin{array}{l}\text { 'Colour circle': perceived } \\
\text { similarity/dissimilarity }\end{array}$ \\
\hline Shepard (1965) & 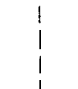 & $\begin{array}{c}x \\
490\end{array}$ & $\begin{array}{c}1 \\
x \\
530\end{array}$ & $\left\{\begin{array}{c}x \\
610\end{array}\right.$ & & $\begin{array}{l}\text { Transformation of } \\
\text { generalization gradients }\end{array}$ \\
\hline Blough (1972) & $\begin{array}{r}x ? \\
460 \\
1\end{array}$ & & $\begin{array}{l}\mid x \\
540 \\
\mid\end{array}$ & $\begin{array}{l}1 x \\
600 \\
1\end{array}$ & & Generalization gradients \\
\hline & 450 & $\frac{1}{500}$ & $\begin{array}{c}1 \\
550 \\
\text { Wavelength }\end{array}$ & $\frac{1}{600}$ & $650 \mathrm{~nm}$ & \\
\hline
\end{tabular}

$x=$ region of good discrimination. $---=$ position of a minimum in the present wavelength discrimination functions. $-=$ failure to find a minimum, which occurs in other studies, although procedure should have detected one ?=feature uncertain, because results were obtained near the end of the stimulus range tested. Note that the experiments by Hamilton and Coleman, Riggs et al., Wright and Cumming and Shepard did not explore far enough into the short-wavelength spectral region to detect a $460 \mathrm{~nm}$ minimum

merton, 1979). The mode of viewing the stimulus has so far been uncontrolled in all experiments on wavelength discrimination.

The wavelength discrimination function, along with other functions, indicates the type of colour vision system operating. The performance of a trichromat is generally characterized by a curve with two well-defined minima (e.g. De Valois and Jacobs, 1968). Whereas previous data (Donner, 1953; Galifret, 1961; Hamilton and Coleman, 1933; Riggs et al., 1972) had suggested that the pigeon's visual system is trichromatic, our experiments indicate greater complexity. The finding of three reproducible minima in the two wavelength discrimination functions indicates that the pigeon has at least tetrachromatic vision. However, the second experiment, covering a more extensive spectral range, suggests pentachromacy. A decrease in thresholds was found at the shortest UV wavelengths tested, whereas steadily increasing threshold values would have been expected if the lower limits of the bird's visible spectrum had been reached. Measurements below $360 \mathrm{~nm}$ were hindered by the glass optics.

The pigeon's optic media transmit UV wavelengths down to at least $310 \mathrm{~nm}$ (Emmerton et al., in press). In the retina 5 types of cone oil-droplets are combined with 3 (Bowmaker, 1979) or even 4 (Govardovskii and Zueva, 1977) cone visual pigments. These combinations provide effective cone spectral sensitivities which correspond well with the post-receptor chromatic mechanisms with maxima at about 410, 480, 545 and $610 \mathrm{~nm}$ (Donner, 1953; Galifret, 1961; Graf and Norren, 1974; Granda and Yazulla, 1971; Ikeda, 1965; Norren, 1975). Besides the short-wavelength sensitive mechanisms mentioned above, the absorption spectra of extracted visual pigments extend into, or have a cis-peak in, the near ultraviolet (Bridges, 1962; Wald, 1958). The pigeon's UV sensitivity could, alternatively, be based on the absorption of UV wavelengths by intermediate products of the photopigments (e.g. metaiodopsin II: Yoshizawa, 1972). The variety of available short-wavelength processing mechanisms may well contribute to the discrepancies in behavioural data in this spectral region.

Pigeons can both detect and orientate themselves by the axis direction of linearly polarized light (see Delius et al., 1976; Kreithen, 1978; Delius and Emmerton, 1979). Polarization of skylight is maximal at UV wavelengths (Sears and Zemansky, 1964). Although the response to polarized light is clearly not specific to UV wavelengths and may be linked to 
hue in a complex way (see Delius and Emmerton, 1979; Delius et al., 1976), we suggest that UV sensitivity may enhance the pigeon's ability to detect skylight polarization patterns. Whether pigeons use their UV detection to aid discrimination of other environmental features as well remains an open question.

Leaving aside considerations about UV sensitivity, there is reason to expect that the positions of minima in wavelength discrimination functions are related to the activity of opponent cells (monkey: De Valois and Jacobs, 1968). Such cells have been described for the pigeon (Yazulla and Granda, 1973). One set of such units showed a rapid change in response at $520 \mathrm{~nm}$ and another at $500 \mathrm{~nm}$, corresponding with the $530 \mathrm{~nm}$ and the $500 \mathrm{~nm}$ minima in the discrimination function. A further class of units with complex opponent properties (Galifret, 1960) showed a response change at $590 \mathrm{~nm}$ corresponding with the $595 \mathrm{~nm}$ minimum. Fitting a quantitative model to the present data, however, must await further information concerning both the psychophysical and physiological processing of colour by pigeons.

We thank the technical staff of the Psychology Department at Durham University for their assistance and, in particular, $\mathrm{Mr}$. D. Harper who collected some of the data in the second experiment. Mrs. C. Thompson gave us much helpful advice about the computer programming. The work was, in part, supported by an SRC Research Grant to J.D. Delius; J. Emmerton received a Durham University Research Studentship. The paper was prepared while the authors were supported by the Deutsche Forschungsgemeinschaft through its Sonderforschungsbereich 114.

\section{References}

Blough, D.S.: Spectral sensitivity in the pigeon. J. Opt. Soc. Am. 47, 827-833 (1957)

Blough, P.M.: Wavelength generalization and discrimination in the pigeon. Percept. Psychophys. 12, 342-348 (1972)

Bowmaker, J.K.: The visual pigments, oil droplets and spectral sensitivity of the pigeon. Vision Res. 17, 1129-1138 (1977)

Bridges, C.D.B.: Visual pigments of the pigeon (Columba livia). Vision Res, 2, 125-137 (1962)

Delius, J.D. : Colour preference shift in hungry and thirsty pigeons. Psychon. Sci. 13, 273-274 (1968)

Delius, J.D., Emmerton, J.A.: Visual performance of pigeons. in: Neural mechanisms of behavior in the pigeon. Granda, A.M., Maxwell, J.H. (eds.). New York: Plenum Press 1979

Delius, J.D., Perchard, R.J., Emmerton, J.A.: Polarized light discrimination by pigeons and an electroretinographic correlate. J. Comp. Physiol. Psychol. 90, 560-571 (1976)

Donner, K.O.: The spectral sensitivity of the pigeon's retinal elements. J. Physiol. (London) 122, 524-537 (1953)

Emmerton, J.A., Schwemer, S., Muth, I., Schlecht, P.: Spectral transmission of the ocular media of the pigeon (Columba livia) Invest. Ophthalmol. Visual Sci. (in press)
Galifret, Y.: Discussion. In: Mechanisms of colour discrimination. Galifret, Y. (ed.), pp. 116-117. London: Pergamon Press 1960

Galifret, Y.: Rétinotopie au niveau tectal et réponses spectrales diencéphaliques chez le pigeon. In: Neurophysiologie und Psychophysik des visuellen Systems. Jung, R., Kornhuber, R. (eds.), pp. 212-215, Freiburger Symposion. Berlin, Göttingen, Heidelberg, New York: Springer 1961

Govardovskii, V.I., Zueva, L.V.: Visual pigments of chicken and pigeon. Vision Res. 17, 537-543 (1977)

Graf, V., Norren, D.V.: A blue sensitive mechanism in the pigeon retina: $\lambda_{\max } 400 \mathrm{~nm}$. Vision Res. 14, 1201-1209 (1974)

Granda, A.M., Yazulla, S.: The spectral sensitivity of single units in the nucleus rotundus of pigeon, Columba livia. J. Gen. Physiol. 57, 363-384 (1971)

Hamilton, W.F., Coleman, T.B.: Trichromatic vision in the pigeon as illustrated by the spectral hue discrimination curve. J. Comp. Psychol. 15, 183-191 (1933)

Ikeda, H.: The spectral sensitivity of the pigeon (Columba livia). Vision Res. 5, 19-36 (1965)

Jitsumori, M.: Wavelength discrimination function derived from post discrimination gradients in the pigeon. Ipn. Psychol. Res. 20, 18-28 (1978)

Kreithen, M.L. : Sensory mechanisms for animal orientation - can any new ones be discovered? In: Animal migration, navigation, and homing. Schmidt-Koenig, K., Keeton, W.T. (eds.), pp. 2534. Berlin, Heidelberg, New York: Springer 1978

Kreithen, M.L., Keeton, W.T.: Detection of polarized light by the homing pigeon, Columba livia. J. Comp. Physiol. 89, 83-92 (1974)

Martin, G.R., Muntz, W.R.A.: Retinal oil-droplets and vision in the pigeon (Columba livia). In: Neural mechanisms of behavior in the pigeon. Granda, A.M., Maxwell, J.H. (eds.). New York: Plenum Press 1979

Norren, D.V.: Two short wavelength sensitive systems in pigeon, chicken and daw. Vision Res. 15, 1164-1166 (1975)

Riggs, L.A., Blough, P.M., Schafer, K.L.: Electrical responses of the pigeon eye to changes in wavelength of the stimulating light. Vision Res. 12, 981-991 (1972)

Schneider, B.: Multidimensional scaling of colour differences in the pigeon. Percept. Psychophys. 12, 373-378 (1972)

Sears, F.W., Zemansky, M.W.: University physics: Part 2. Reading, Mass. : Addison-Wesley 1964

Shepard, R.N. : Approximation to uniform gradients of generalization by monotone transformation of scale. In: Stimulus generalization. Mostofsky, D.I. (ed.), pp. 94-110. Stanford: University Press 1965

Valois, R.L. De, Jacobs, G.H.: Primate colour vision. Science 162, 533-540 (1968)

Wald, G.: The Selig Hecht commemorative lecture. Nat. Phys. Lab. Symp., No. 8, 7-61 HMSO, London 1958

Wright, A.A. : Psychometric and psychophysical hue discrimination functions for the pigeon. Vision Res. 12, 1447-1464 (1972a)

Wright, A.A. : The influence of ultraviolet radiation on the pigeon's colour discrimination. J. Exp. Anal. Behav. 17, 325-337 (1972 b)

Wright, A.A., Cumming, W.W.: Colour naming functions for the pigeon. J. Exp. Anal, Behav. 15, 7-17 (1971)

Yazulla, S., Granda, A.M. : Opponent-colour units in the thalamus of the pigeon (Columba livia). Vision Res. 13, 1555-1563 (1973)

Yoshizawa, T.: The behaviour of visual pigments at low temperatures. In: Handbook of sensory physiology, Vol. VII/1. Dartnall, H.J.A. (ed.), pp. 146-179. Berlin, Heidelberg, New York: Springer 1972 